\title{
ПРЕДПОСЫЛКИ РАЗВИТИЯ СФЕРЫ УСЛУГ В СЕЛЬСКОЙ МЕСТНОСТИ В УСЛОВИЯХ ЦИФРОВОЙ ЭКОНОМИКИ
}

\author{
(c) 2020 Макаров Владимир Васильевич \\ доктор экономических наук, профессор \\ Санкт-Петербургский государственный университет телекоммуникаций \\ им. проф. М.А.Бонч-Бруевича, Россия, Санкт-Петербург \\ E-mail: akad.makarov@mail.ru \\ (c) 2020 Фёдорова Марина Юрьевна \\ преподаватель \\ Санкт-Петербургский государственный университет телекоммуникаций \\ им. проф. М.А.Бонч-Бруевича, Россия, Санкт-Петербург \\ E-mail:m.fyodorova@gmail.com
}

В статье рассмотрены тенденции развития различных видов связи и из них выделены наиболее динамично развивающиеся. Так как в условиях цифровой экономики работники сферы услуг, занимающиеся предоставлением услуг он-лайн, менее зависимы от своего места жительства, развитие сети Интернет может положительно сказываться на развитии данного сектора в сельской местности и повышении занятости местных жителей. Данные о том, как население и организации используют глобальную сеть свидетельствуют о большом количестве взаимодействий между поставщиком и потребителем услуг именно в сети Интернет. В связи с этим мы также полагаем, что в настоящее время формируются предпосылки ведения трудовой или предпринимательской деятельности сельскими жителями в сети Интернет.

Ключевые слова: сфера услуг в сельской местности, удаленная занятость, циффровая экономика, постиндустриальная экономика, человеческий капитал, услуги он-лайн

На данный момент среди отечественных и зарубежных ученых осуществлено не так много исследований на предмет взаимосвязи развития сети Интернет или услуг связи и сферы услуг. По большей части исследования в данной области ведутся в более широком смысле, где речь идет о влиянии развития телекоммуникационных услуг на экономическое развитие.

В то же время в эпоху цифровой экономики все большее значение начинают играть не материальные ресурсы, а информация, человеческий капитал, а сфера услуг, услуги образования, туризм и рекреация, здравоохранение, финансы и т.д. становится основной деятельностью. В связи с этим мы говорим о развитии постиндустриальной экономики, которая неразрывно связана с цифровой экономикой, а также открывает новые возможности для получения дополнительного или основного заработка именно тем территориям, а значит и их жителям, которые ранее ввиду своего географического положения или отсутствия материальных ресурсов находились в менее выгодной позиции.

Например, по результатам исследования
Бертчек И. и др. компании сферы услуг, особенно те в которых требуются исполнители со специальными навыками, выступают основными бенефициарами широкого распространения широкополосного Интернета [1].

Согласно исследованию канадских ученых Ивус О. и Боланд М. развитие широкополосного Интернета положительно сказывается на развитии сферы услуг, особенно в сфере IT, именно в сельской местности, а на производство группы товаров промышленного назначения не оказывает никакого влияния [2].

В исследованиях Колко Дж. мы видим, что самые зависимые от развития широкополосного Интернета - специалисты в сфере IT. Такие виды услуг как услуги менеджмента крупных компаний, разного рода исследовательские услуги, технические и информационные услуги также показали себя как положительно зависимые от развития сети Интернет на территории. В то же время Колко Дж. не выявил значимой зависимости развития таких услуг как образовательные, услуги здравоохранения, социальные услуги, искусство, услуги развлечения и рекре- 
ации, от развития широкополосного Интернета [3]. Здесь следует отметить тот факт, что и сам исследователь предостерегал, что в будущем временном периоде такая зависимость может быть видоизменена. В связи с этим мы выдвигаем гипотезу, что в настоящее время развитие сети Интернет также может способствовать развитию образовательных услуг и услуг в области развлечения и рекреации.

Например, в своем докладе «Цифровая Россия» компания McKinsey утверждает, что с помощью «цифровых кадров» в нашей стране можно снизить прогнозируемый недостаток в кадрах, связанный со снижением трудоспособного населения. Кроме того, цифровизация оказывает влияние на работу компаний по всему миру, которые готовы привлекать в свой штат исполнителей для удаленной работы из любой точки мира [4]. Но все это требует либо повышения квалификации будущего персонала, либо профессиональной переподготовки, что и обуславливает необходимость в образовательных услугах.

Также подробно рассматривают количественные и качественные особенности цифровой экономики в условиях Российской Федерации и обозначают необходимые векторы развития Блатова Т.А., Макаров В.В., ШувалСергеева Н.С. [5].

Какие услуги связи наиболее востребованы в данный момент можно оценить по данным экономических показателей за период 2009-2019 гг. (Рисунок 1).

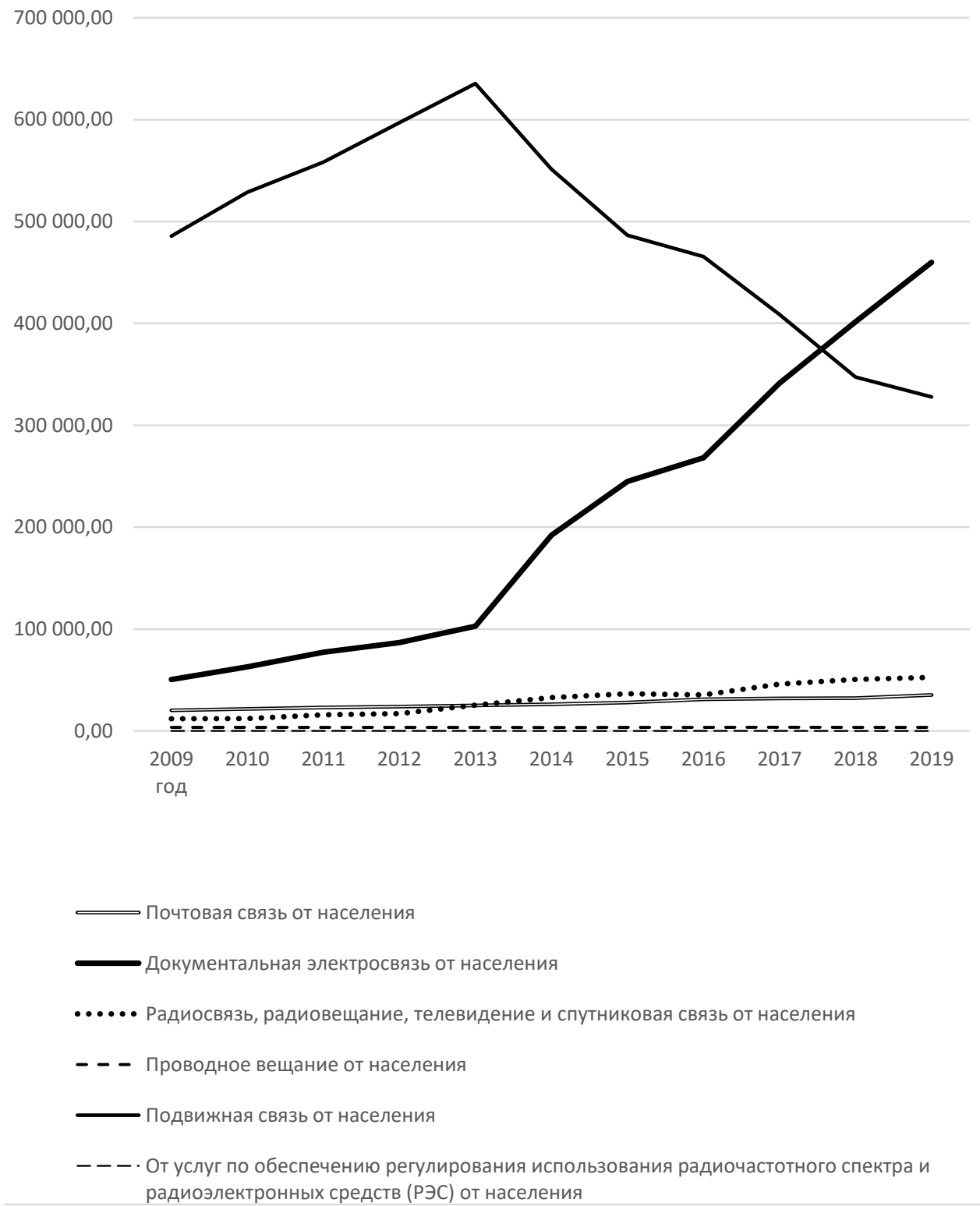

Рисунок 1. Доходы от предоставления населению услуг связи за период 2009-2019 гг., млн. руб. (источник: составлено авторами по данным Министерства цифрового развития, связи и массовых коммуникаций РФ) 
По этим данным видно, что более всего доходов от населения Министерство цифрового развития, связи и массовых коммуникаций РФ получает от таких видов связи как «подвижная связь» и «документальная электросвязь». Несмотря на высокие начальные показатели, доходы от услуг предоставления подвижной связи населению с 2013 года стремительно падают, и с 2017 года они уже ниже, чем доходы от предоставления населению документальной электросвязи. Мы также видим, что доходы от предоставления населению таких видов связи как «радиосвязь, радиовещание, телевидение и спутниковая связь», «почтовая связь», «проводное вещание», «обеспечение регулирования использования радиочастотного спектра и радиоэлектронных средств (РЭС)» в течение всего периода значительно меньше лидирующих позиций, но не превышают 100000 млн. рублей.

При более детальном рассмотрении доходов от населения от разных видов связи также видно, что есть доходы от населения, хоть и не такие высокие, но с положительной тенденцией: от предоставления услуг радиосвязи, радиовещания, телевидения и спутниковой связи, а также от предоставления услуг почтовой связи (Рисунок
2). Следует также отметить, что если в 2016 году доходы от предоставления услуг радиосвязи, радиовещания, телевидения и спутниковой связи несколько снизились, а потом резко возросли, то в этом же году доходы от предоставления услуг почтовой связи продолжили свой положительный рост и только в следующем году незначительно снизились. Эти доходы растут, что также говорит о том, что количество подключений и покрытия данными видами связи растет (Рисунок 1, Рисунок 2), чего нельзя сказать о подвижной связи; так как в данной области в последнее время становится все сложнее наращивать абонентскую базу.

Что касается доходов, получаемых от населения за предоставление услуг проводного вещания и доходов от предоставления услуг радиосвязи, радиовещания, телевидения и спутниковой связи, они значительно ниже доходов, получаемых от населения за предоставление услуг «документальной связи».

Полученные данные о том, что услуги по предоставлению документальной электросвязи являются наиболее динамичными (Рисунок 1) и постоянно растут, дают основание полагать, что спрос на них со стороны населения в насто-

60000,00

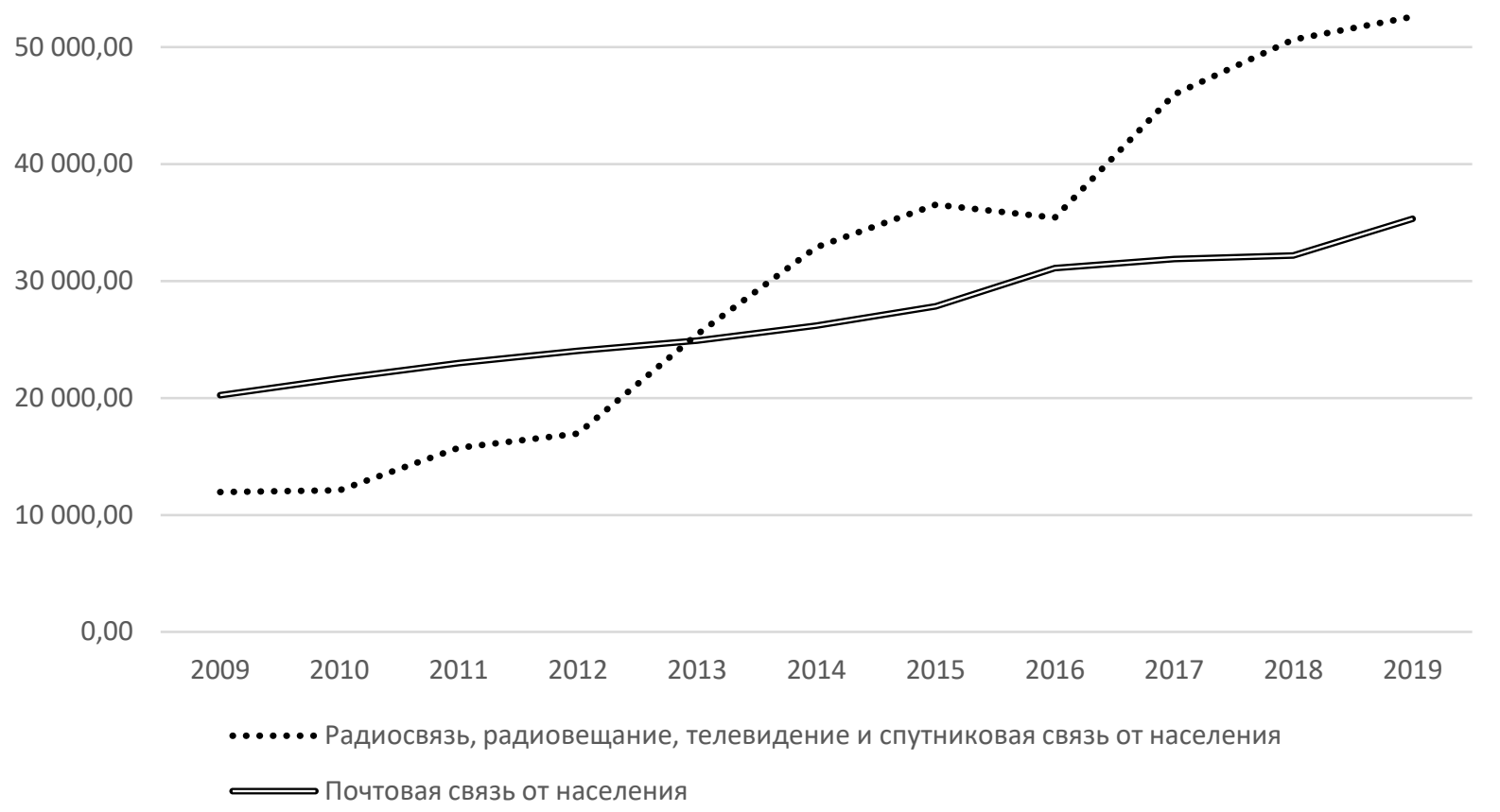

Рисунок 2. Доходы от предоставления населению услуг связи за период 2009-2019 гг, млн. руб. (источник: составлено авторами по данным Министерства цифрового развития, связи и массовых коммуникаций РФ) 
ящий момент растет. Это позволяет выдвинуть гипотезу о том, что потребление разного рода контента с помощью электронных средств и услуг документальной электросвязи особенно востребовано, так как сеть Интернет сегодня - это своего рода среда, где встречаются «поставщик услуг» и «потребитель услуг», что объясняется условиями цифровой экономики.

Из данных в Таблице 1 мы видим, что среди населения, использующего сеть Интернет, в последнее время наиболее динамично растет доля сельского населения, а в городской среде доля населения, использующего сеть Интернет, растет значительно медленнее. Это по большей части можно объяснить низкой начальной скоростью проникновения сети Интернет в сельскую местность, что на начальном этапе появления сети Интернет стало причиной цифрового неравенства. Все же не следует забывать, что пока еще миграция из села в города остается проблемой, так как численность сельского населения снижается. В то же время исследованиях Ивус О. и Боланд М. мы также видим, что развертывание широкополосной связи сокращает региональные различия в возможностях трудоустройства и повышает экономическую жизнеспособность сельских регионов [2]. И это одна из основных причин, почему необходимо устранять цифровое неравенство, и поэтому данные и росте доли сельского населения, использующего сеть Ин- тернет, выглядят позитивно.

Согласно статистическим данным удельный вес населения, использующего сеть Интернет ежедневно, также с каждым годом растет (Таблица 2). Особенно важно, что организации и население с каждым годом все больше используют сеть Интернет для взаимодействия и осуществления разного рода сделок (Таблица 2). В связи с этим мы, поддерживая мнение о том, что повышение самозанятости местного населения один из наиболее перспективных способов снижения безработицы в сельской местности $[7 ; 8]$, полагаем, что в новых условиях роста цифровых сделок и постепенного проникновения сети Интернет в сельскую местность самозанятость следует повышать именно в сети Интернет: занимаясь предоставлением разных услуг или же используя сеть Интернет для продвижения и реализации своих услуг.

Исследования в области использования сети Интернет среди сельских предпринимателей, осуществленные Папандреа Ф. и Вейд М., показали, что все опрошенные используют свои сайты для продвижения и реализации продукции. Только один из предпринимателей ответил, что Интернет-сайт в его деятельности бесполезен [11]. К этому следует добавить, что сегодня полезность Интернет-сайтов нивелируется популярностью социальных сетей, поэтому некоторые предприниматели вообе отказываются

Таблица 1. Население, использующее сеть Интернет, по типу местности, в\% от общей численности населения (источник: сформировано авторами по материалам Статистических сборников «Информационное общество в Российской Федерации». [5; 6])

\begin{tabular}{|l|c|c|c|c|c|}
\hline & 2014 & 2015 & 2016 & 2017 & 2018 \\
\hline Городская местность & 78.7 & 81.7 & 84.3 & 86.8 & 83.4 \\
\hline Сельская местность & 60.4 & 65.5 & 70.3 & 74.3 & 80.3 \\
\hline
\end{tabular}

Таблица 2. Удельный вес населения и организаций, использующих Интернет для личных и предпринимательских целей,\% (источник: сформировано авторами по материалам Статистических сборников «Информационное общество в Российской Федерации». [9; 10; 6])

\begin{tabular}{|c|c|c|c|c|c|c|}
\hline & 2013 & 2014 & 2015 & 2016 & 2017 & 2018 \\
\hline $\begin{array}{l}\text { Удельный вес населения, использующего сеть } \\
\text { Интернет ежедневно в общей численности } \\
\text { населения, \% }\end{array}$ & 48.1 & 51.6 & 55.1 & 57.7 & 60.6 & 68.8 \\
\hline $\begin{array}{l}\text { Удельный вес организаций, использующих сеть } \\
\text { Интернет для взаимодействия с поставщиками, } \\
\text { в общем числе организаций, \% }\end{array}$ & 67.1 & 66.1 & 66.4 & 66.7 & 67.7 & 69.8 \\
\hline $\begin{array}{l}\text { Удельный вес организаций, использующих сеть } \\
\text { Интернет для взаимодействия с потребителями, } \\
\text { в общем числе организаций, \% }\end{array}$ & 47.5 & 46.2 & 46.8 & 48.2 & 49.0 & 51.7 \\
\hline
\end{tabular}


от собственных сайтов, осуществляя продажи, продвижение и общение с потребителями услуг в социальных сетях. Это также необходимо принимать во внимание при осуществлении предпринимательской деятельности в сети Интернет.

Одной из особенно перспективных сфер нам представляется развитие Интернет-коммерции [12]. В сельской местности развитие сферы услуг в сети Интернет может приобретать измененные образы [13] с учетом культурного и природного потенциала территории и ее человеческого капитала. Развитие Интернет-коммерции в сельской местности могло бы послужить толчком к развитию предпринимательской активности местных жителей и повышению занятости местного населения. В исследованиях Маркли Д. М. и др. [14], а также Запата С.Д. и др. [15] мы тоже видим, что сельские предприниматели используют сеть Интернет для продвижения своих услуг. Кроме того создание специальных платформ, маркетплейсов, где сельские предприниматели также могут предлагать свои услуги, выводит сельских предпринимателей на новый уровень реализации своих услуг.

В исследованиях Фёдоровой М.Ю. и Александрова И.Н. [16] мы видим, что сельские жители заинтересованы в дополнительном заработке и большая часть жителей хотела бы зарабатывать с использованием новых возможностей сети Интернет. Но на данный момент местное население не владеет необходимой информацией и навыками, чтобы начать вести предпринимательскую деятельность в этой области.

В свете роста доходов от услуг по предоставлению документальной электросвязи населению, рассмотрим цели использования сети Интернет населением (Таблица 3). Потребление разного рода контента в сети Интернет растет от года в год, так же как и разнообразие и разновидности этого контента, который представлен только обобщенно в данном статистическом исследовании и выборочно в нашем исследовании с целью продемонстрировать те виды услуг, спрос на которые растет уже сейчас.

Сфера услуг сегодня функционирует и активно развивается в цифровом пространстве. Мы также видим постоянный рост услуг по предоставлению населению документальной электросвязи (Рисунок 1). Поэтому мы полагаем, что для индивидов изменяются и облегчаются условия выхода на рынок и ведения бизнеса, появляются новые возможности ведения предпринимательской деятельности в сфере услуг в сети Интернет, которая не требует от потенциального предпринимателя жизни в городской местности. В качестве «услуг» может выступать как контент разного рода (видео, аудио, текстовые сообщения для удовлетворения образовательных, рекреационных развлекательных, бизнес целей потребителей данных услуг), так и «услуга» по поиску, предоставлению информации, заключению сделки и организации доставки до конечного потребителя какого-то физического товара, если мы говорим об Интернет-коммерции. Тем не менее данные возможности на сегодняшний момент лимитированы низкой предпринимательской грамотностью и грамотностью в области поиска работы или предоставления разного рода услуг или ведения предпринимательской деятельности во всемирной сети, что было подтверждено в наших предыдущих исследованиях. В связи с этим мы полагаем, что несмотря на позитивные предпосылки к развитию сферы услуг в цифровой среде или использованию цифровой среды для продвижения и / или реализации услуг в или из сельской местности, эти предпосылки ограни-

Таблица 3. Цели использования сети Интернет населением, в\% от общей численности населения, использующего сеть Интернет) (источник: сформировано авторами по материалам Статистических сборников «Информационное общество в Российской Федерации». [5; 6])

\begin{tabular}{|l|c|c|c|c|c|}
\hline & 2014 & 2015 & 2016 & 2017 & 2018 \\
\hline $\begin{array}{l}\text { Скачивание фильмов, изображений, музыки; } \\
\text { просмотр видео; прослушивание музыки или радио }\end{array}$ & 49.5 & 49.6 & 51.4 & 49.2 \\
\hline Поиск информации о товарах и услугах & 37.0 & 39.6 & 43.8 & 51.7 & 54.1 \\
\hline $\begin{array}{l}\text { Чтение или скачивание онлайновых газет } \\
\text { или журналов, электронных книг }\end{array}$ & 19.2 & 21.1 & 22.1 & 25.0 & 22.9 \\
\hline $\begin{array}{l}\text { Продажа/покупка товаров и услуг } \\
\text { (в том числе с помощью сайтов-аукционов) }\end{array}$ & 14.5 & 15.3 & 17.5 & 18.9 & 24.9 \\
\hline $\begin{array}{l}\text { Поиск информации об образовании, } \\
\text { курсах обучения, тренингах и т.п. }\end{array}$ & 9.4 & 8.8 & 9.0 & 11.7 & 8.8 \\
\hline Дистанционное обучение & 3.0 & 2.9 & 2.7 & 3.6 & 3.1 \\
\hline
\end{tabular}


чены, во-первых, низкой предпринимательской грамотностью и грамотностью в области поиска работы или ведения бизнеса в глобальной сети; во-вторых, недостаточной цифровизацией сельской местности. В связи с этим мы предлагаем вести работу по повышению предпринимательской грамотности, а также грамотности в обла- сти осуществления разных видов трудовой деятельности в сети Интернет. Но данные действия могут быть реализованы только при достаточном покрытии в сельской местности, поэтому необходимо, чтобы каждый житель сельской местности имел возможность быть подключенным к глобальной сети.

\section{Библиографический список}

1. Bertschek, I., Briglauer, W., Hüschelrath, K., Kauf, B., Niebel T., The Economic Impacts of Telecommunications Networks and Broadband Internet: A Survey. Discussion Paper No. 16-056.- Centre for European Economic Research, 2016, $51 \mathrm{p}$.

2. Boland, M., Ivus, O., The Employment and Wage Impact of Broadband Deployment in Canada // Canadian Journal of Economics. - 2015. - Vol. 48(5) - P. 1803-1830 DOI: 10.1111/caje.12180

3. Kolko, J., Broadband and local growth // Journal of Urban Economics. - 2011. - Vol. 71(1) - P. 100-113.

4. Цифровая Россия: новая реальность.- Digital McKinsey, 2017 URL: https://www.tadviser.ru/images/c/c2/ Digital-Russia-report.pdf

5. Блатова Т.А., Макаров В. В., Шувал-Сергеева Н.С., Количественные и качественные аспекты измерения цифровой экономики // Радиопромышленность. - 2019 - № 4- С. 63-72

6. Лайкам К. Э., Абдрахманова Г. И., Гохберг Л. М., Дудорова О. Ю. и др. Информационное общество в Российской Федерации.- Москва: НИУ ВШЭ, 2017, 328 с.

7. Ильин А.Е., Савин Д. А., Конорев А. М., Безработица сельского населения: состояние и пути снижения // Вестник Курской государственной сельскохозяйственной академии - 2012.- № 3 - С. 47-49.

8. Макаров В.В., Цатурова Р. Г., Мазурова М. М., Горбачев В. Л. Менеджмент в телекоммуникациях. 2-е изд., перераб. и доп.-Санкт-Петербург, 2011.

9. Сабельникова М. А., Абдрахманова Г. И., Гохберг Л. М., Дудорова О. Ю. и др. Информационное общество в Российской Федерации. 2019.- Москва: НИУ ВШЭ, 2019.

10. Сабельникова М. А., Абдрахманова Г. И., Гохберг Л. М., Дудорова О. Ю. и др. Информационное общество в Российской Федерации. 2018. - Москва: НИУ ВШЭ, 2018.

11. Papandrea, F., Wade, M., E-commerce in Rural Areas - Case studies Rural Industries Research and Development Corporation, 2000. 00/185.- 2000. URL: https://www.agrifutures.com.au/wp-content/uploads/ publications/00-185.pdf

12. Макаров В.В., Колотов Ю. О. Развитие Интернет-коммерции // Экономический анализ: теория и практика.2009 - № 26(155) - С. 60-64.

13. Фёдорова М.Ю., АлександровИ.Н. Развитие предпринимательства в сельских поселениях с помощью цифровизации как фактор развития региональной экономики // Евразийский международный научноаналитический журнал «Проблемы современной экономики». - 2019. - № 4(72) - С. 156-159.

14. Markley, D. M., Barkley, D. L., Lamie R. D., Case Studies of E-Commerce Activity In Rural And Small Town Businesses.Clemson University, 2007 URL: https://ageconsearch.umn.edu/bitstream/112894/2/E-Commerce\%20Project.pdf

15. Zapata, S.D., Isengildina, O., Carpio, C., Lamie D., Do Internet-based Promotion Efforts Work? Evaluating MarketMaker // Journal of Agribusiness. - 2011 - Vol. 29(1) - P. 159-180

16. Fedorova M. Yu., Aleksandrov I. N., Digital economy and green economy: rural unemployment and territorial selfdevelopment in Russia // E3S Web of Conferences. - 2019 - Vol. 110(2) DOI: 10.1051/e3sconf/201911002019 